\title{
Salt as a public health challenge in continental European convenience and ready meals
}

\author{
Sonja Kanzler, Christina Hartmann, Anita Gruber, Guido Lammer and \\ Karl-Heinz Wagner* \\ Department of Nutritional Sciences, 'Emerging Field Oxidative Stress and DNA Stability', University of Vienna, \\ Althanstraße 14, 1090 Vienna, Austria
}

Submitted 20 August 2013: Final revision received 25 February 2014: Accepted 20 March 2014: First published online 8 May 2014

\begin{abstract}
Objective: To assess the salt content of continental European convenience and ready meals.

Design: A multistage study in which, after laboratory analysis of the products' salt contents ( $n$ 32), new salt-reduced meals were developed through food reformulation. Additionally, a comprehensive survey of convenience meals from the Austrian market ( $n$ 572) was conducted to evaluate the salt contents of a wider product range.

Setting: Six continental European countries participated.

Subjects: No subjects enrolled.

Results: The salt contents of continental European convenience and ready meals mostly exceeded $1.8 \mathrm{~g} / 100 \mathrm{~g}$, which is $30 \%$ of the targeted daily intake level; some contained even more than the recommended daily intake of $6 \mathrm{~g}$. The highest salt contents were found in pizzas and pasta dishes, the lowest ones in sweet meals. Large variations in salt levels were found not only between and within meal type categories, but also between similar meals from different producers. In addition, our approach to develop new salt-reduced meals showed that a stepwise reduction of the ready meals' salt contents is possible without compromising the sensory quality.

Conclusions: To address the problem of hypertension and increased risk for CVD through high salt intake, a reduction of the salt levels in continental European convenience and ready meals is urgently needed, since they are providing a major part of the daily salt intake. Successful national-wide salt reduction strategies in the UK or Finland have already demonstrated the public health impact of this setting.
\end{abstract}

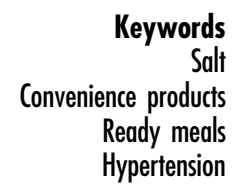

Non-communicable diseases including CVD, diabetes, cancer and chronic respiratory diseases are the leading cause of death worldwide. Raised blood pressure as a major single risk factor for CVD is estimated to cause 7.5 million deaths per year (12.8\% of all global deaths $)^{(1)}$.

There is conclusive evidence that a high salt intake is associated with hypertension, which consequently increases the risk for CVD such as stroke or $\mathrm{CHD}^{(2-4)}$. To reduce blood pressure a limited salt intake is recommended and for adults should not exceed $6 \mathrm{~g} / \mathrm{d}$ according to different expert committees $^{(4-8)}$ or $5 \mathrm{~g} / \mathrm{d}$ according to the $\mathrm{WHO}^{(3)}$.

The cost-effectiveness of salt reduction programmes to reach these intake levels and to prevent CVD has been demonstrated recently ${ }^{(9-13)}$. A saving of \$US 10-24 billion in annual health-care costs with a population-wide reduced salt intake of $3 \mathrm{~g} / \mathrm{d}$ has been estimated ${ }^{(10)}$. According to a recent WHO report, 'a reduced salt intake and salt content of food' is considered to be a 'best-buy' action that should be implemented as soon as possible to save lives by preventing diseases ${ }^{(1)}$.

Besides the effects on blood pressure, a high salt intake may lead to the progression of renal disease, renal stones and stomach cancer and may be linked to the severity of asthma $^{(2)}$.

Despite these reports, the current average daily salt intake of most adult populations exceeds $6 \mathrm{~g} / \mathrm{d}$ and in many, especially Asian, countries even $12 \mathrm{~g} / \mathrm{d}$. Also for children older than 5 years of age excessive salt intakes have been reported $^{(14)}$. In Austria $47 \%$ of women, $60 \%$ of men, $72 \%$ of girls and $78 \%$ of boys (both aged $7-14$ years) have salt intakes above $6 \mathrm{~g} / \mathrm{d}^{(15)}$.

In European and North American diets, most of the dietary sodium results from sodium chloride added to manufactured food (approximately $75 \%$ of intake in the USA and the UK) ${ }^{(16,17)}$. The main contributors are cereals and cereal products (including bakery products, pasta, rice 
and breakfast cereals) as well as meat and meat products (including bacon, ham, sausages and meat dishes) ${ }^{(18-21)}$. Since the importance of convenience foods including fast foods, takeaways and ready meals is increasing steadily ${ }^{(22-24)}$, the salt content of this product group has to be considered when assessing the daily salt intake. Particularly the salt contents of fast food and takeaway meals are alarmingly high ${ }^{(25-28)}$. The salt concentrations of convenience foods including ready meals, soups or pizzas that are available on the Australian and British market showed high variations within meals of the respective food groups (e.g. pizzas) ${ }^{(21,29-33)}$. The same was true for the salt content of fast foods, which varied not only by the type of food, but also by producer and country of origin ${ }^{(25)}$.

The combination of food reformulation with improved food labelling and initiatives to raise consumer awareness has already led to successful national-wide salt reduction programmes, e.g. in Finland and the $\mathrm{UK}^{(34-36)}$.

Since the market for convenience products is growing steadily in continental Europe, there is a strong need to assess salt in ready meals and to develop further strategies to lower current salt intake levels as a public health tool.

Our aim was to assess the salt content of continental European ready meals within the European research project 'Double Fresh'. The objective of the project was to raise the overall quality of these meals. Therefore experts from different food science areas and nutrition worked together with small- and medium-sized enterprises to improve sensory properties and nutritional composition and cover the food safety aspects of these meals (project no. FOOD-CT-2006-23182; www.doublefresh.eu).

To assess the salt content our investigations were divided into three sequenced sections. First, ready meals offered on the continental European market were analysed in the laboratory. In the second stage, our objective was to assist the food company partners in developing new salt-reduced products and to evaluate the process of meal reformulation. Hence, we established basic, easily understandable nutritional guidelines and further analysed the salt levels of the newly developed meals. In order to include a higher number of meals, we comprehensively evaluated the labelled salt contents of convenience foods sold by Austrian retailers.

\section{Experimental methods}

\section{Samples}

Ready meals from the European market (n 32)

A total of thirty-two ready meals offered to European consumers in supermarkets were investigated.

All meals met the definition of home-meal replacements published by Costa et al. ${ }^{(37)}$. They represented main dishes comprising all typical components (a protein component such as meat/fish, a starchy component such as rice/potatoes/ noodles, vegetables and/or a sauce). No addition of further ingredients was necessary in the course of preparation. The meals were chilled ( $n$ 25), frozen $(n 5)$ or stored at room temperature ( $n$ 2).

Of the analysed ready meals, $63 \%$ contained meat, $16 \%$ were meat products (sausages or bacon) and $16 \%$ contained fish (salmon, catfish or pollock). The remaining $5 \%$ were vegetarian meals. The starchy component in $41 \%$ of all analysed ready meals was rice, $25 \%$ contained potatoes, $22 \%$ noodles and $16 \%$ of all meals included other components (e.g. dumplings). Nearly all meals contained a sauce and half of the meals different vegetables, legumes or fruits in an amount of more than $10 \%$ $(\mathrm{w} / \mathrm{w})$. The detailed ingredient lists according to the producer labelling are presented in the online supplementary material, supplemental Table S1.

Twelve ready meals were provided from food industry partners of the 'Double Fresh' project. Of those ready meals five originated from the Scandinavian region, five from the Benelux countries and another two from Central Europe. The twenty Austrian ready meals from the most popular brands were sampled at retailers (leading markets as well as discount markets).

The main selection criteria were sales figures (available through personal contact with food companies) and the food type. Frequently sold meals are often eaten and hence have a greater impact on consumers' health than other meals.

\section{Newly developed ready meals (n 7)}

As already described the food industry partners developed seven supposedly salt-reduced meals, which were analysed for their salt contents. All of these meals were chilled and met the above-mentioned definition of home-meal replacements. From these meals, four contained meat, two meals fish (salmon) and one meal was vegetarian. As side dish rice was chosen for two meals, noodles for two meals and potatoes for three meals. All of the analysed optimized meals contained vegetables and a sauce. The lists of ingredients are available in supplemental Table S1.

\section{Convenience foods from the Austrian market (n 572)}

For a comprehensive survey of convenience foods from the Austrian market, ready meals that met the abovementioned criteria but also main dishes without accompaniment, soups, hot sweet dishes (except for desserts), cold sandwiches and salads were sampled one year after the laboratory analyses. All meals were ready-made and only had to be heated before consumption either without adding any further ingredients or with adding some water, milk and/or oil. Fourteen of the twenty laboratoryanalysed meals were still available on the market and thus included in the survey.

The collected ready meals were categorized into the following meal types: soups, pasta dishes, meat meals, pizzas, sweet meals, cold meals, salads, savoury dumplings, meals with potatoes/legumes/grains, fish meals and other meals. 
The definitions of each category including some examples can be found in the online supplementary material, supplemental Table S2.

\section{Analyses}

\section{Sample preparation}

Ready meals were heated with a microwave oven on the respective last days of shelf life as instructed on the packages (time and wattage). One meal was heated with an electric cooker and another one in the oven.

After preparation the meals were weighed, immediately cooled on dry ice, homogenized (Mixer B-400; Büchi, Flawil, Switzerland) and stored at $-80^{\circ} \mathrm{C}$ under nitrogen head space until further analyses (no longer than 4 weeks).

The edible portion of each meal was $100 \%$. The sample size was one package, which was in most cases equivalent to one serving.

Five sub-samples per meal were taken for the nonAustrian and two for the Austrian meals. The sub-samples were selected from the same batch and analysed in duplicate.

\section{Determination of the salt content}

The chloride or sodium present in the meals is added as salt during food processing. Consequently, the salt content can be calculated stoichiometrically from the ready meals' chloride content, which was determined by a modified method of Mohr ${ }^{(38)}$. The method's reproducibility was verified by calculating relative standard deviation from measuring a control food sample (beef goulash with noodles) ten times on one day and alongside the regular samples' analyses. The mean value for salt was $1.18 \mathrm{~g} / 100 \mathrm{~g}$. The relative standard deviation from one day was $1.67 \%$ and between days was $1.59 \%$.

\section{Systemic survey of Austrian convenience foods}

Data collection process

A total of 572 Austrian convenience foods from eight major food manufacturers (Knorr, Chef Menü, Iglo, Inzersdorfer, Wagner, Maggi, Spar Feine Küche and Dr. Oetker) and from one company providing organic products (Natur Compagnie) were included in the study. Data were collected at the supermarkets or from the companies' web pages or by personal contact with the companies. In-store data were recorded either by manual transcription into a record book or by photography of the item. All data were entered into a bespoke spreadsheet.

\section{Product information collected}

For each convenience food the brand name, product name, manufacturer, package size, number of portions per package, complete list of ingredients and the declaration of nutrients were collected. If only the sodium content was declared, salt was calculated by multiplying by 2.542 .
Data presentation, comparison with recommended dietary salt intake levels and statistical analyses

All data were calculated per $100 \mathrm{~g}$ as well as per serving. From the collected data the number of products, the mean or median (depending on data distribution) and the range of salt contents were calculated in total, by meal category and by company.

The numbers of meals containing salt concentrations higher than the published targeted average salt intake level of $6 \mathrm{~g} / \mathrm{d}^{(4-8)}$ and the WHO recommendation of $5 \mathrm{~g} / \mathrm{d}^{(3)}$ for a main meal ( $=30 \%$ of the RDA) as well as for daily intake (100\%) were calculated.

The mean salt content of the ready meals originally available on the European market was compared with that from the newly developed ready meals with a Student's $t$ test since all data were normally distributed. To determine whether there were differences between the Austrian convenience foods depending on the meal type category and the producing company, the data (not normally distributed) were analysed by performing both the Kruskal-Wallis $H$ test and the Mann-Whitney $U$ test with Bonferroni adjustment for multiple testing. Statistical differences were considered significant at $P<0 \cdot 05$. All statistical analyses were performed using the statistical software package IBM SPSS Statistics version $20 \cdot 0$ for Microsoft Windows.

\section{Results and discussion}

The analysed salt concentrations of ready meals offered at European supermarkets and of the newly developed supposedly salt-reduced meals are shown in Table 1 . The results of the comprehensive survey of Austrian convenience products overall and divided into the various meal type categories are shown in Table 2.

\section{Ready meals available on the continental European market (n 32)}

Salt contents in $\mathrm{g} / 100 \mathrm{~g}$

In total, the average salt content was $1.38 \mathrm{~g} / 100 \mathrm{~g}$. The salt contents of most meals ranged from $1 \mathrm{~g} / 100 \mathrm{~g}$ to $2 \mathrm{~g} / 100 \mathrm{~g}$ (Table 1). Salt content of $<1 \mathrm{~g} / 100 \mathrm{~g}$ was found in salmon with pasta and vegetables; salmon with potatoes and sauce; chicken risotto with mango sauce; and chicken with carrots, peas and potatoes. The highest contents of $>2 \mathrm{~g} / 100 \mathrm{~g}$ were found in roast pork with dumplings and Chinese chicken with rice. Significant differences in salt based on meal types (e.g. meat-based $v$. fish-based $v$. vegetarian) were not found.

Comparison of the salt contents (g/portion) with the targeted daily salt intake levels

The salt concentration per portion varied from $3.36 \mathrm{~g}$ to $7 \cdot 72 \mathrm{~g}$, with an average of $5 \cdot 16 \mathrm{~g} /$ portion. Since all of the 
Table 1 Salt content per $100 \mathrm{~g}$ edible portion and per serving of thirty-two European ready meals and of seven newly developed ready meals

\begin{tabular}{|c|c|c|c|c|c|c|}
\hline \multirow[b]{2}{*}{ Food name } & \multirow[b]{2}{*}{$n$} & \multicolumn{3}{|c|}{$\begin{array}{c}\text { Salt } \\
(\mathrm{g} / 100 \mathrm{~g})\end{array}$} & \multirow{2}{*}{$\begin{array}{l}\text { Portion size }{ }^{*} \\
\text { (g) }\end{array}$} & \multirow{2}{*}{$\frac{\begin{array}{c}\text { Salt } \\
\text { (g/portion) }\end{array}}{\text { Mean }}$} \\
\hline & & Mean & Min & Max & & \\
\hline \multicolumn{7}{|l|}{ Currently available ready meals } \\
\hline Chicken with rice and curry sauce & 5 & 1.30 & $1 \cdot 27$ & 1.38 & 300 & 3.91 \\
\hline Chicken risotto with mango sauce & 5 & 0.97 & 0.93 & 1.02 & 410 & 3.95 \\
\hline Chicken with carrots, peas, potatoes & 5 & 0.74 & 0.71 & 0.77 & 500 & 3.72 \\
\hline Chicken risotto & 5 & 1.52 & 1.47 & 1.57 & $310+$ & 4.72 \\
\hline Chicken curry with rice & 2 & $1 \cdot 19$ & 1.19 & $1 \cdot 19$ & 400 & 4.76 \\
\hline Asian rice dish with chicken & 2 & 1.84 & 1.80 & 1.87 & 350 & $6 \cdot 44$ \\
\hline Chinese chicken with rice & 2 & 2.06 & 2.00 & $2 \cdot 11$ & 330 & $6 \cdot 78$ \\
\hline Chicken with mushrooms and rice & 2 & 1.02 & 1.01 & 1.02 & 330 & 3.36 \\
\hline Brun lapskaus & 5 & 1.31 & 1.28 & 1.35 & $400+$ & $5 \cdot 25$ \\
\hline Pork in spicy tomato sauce with rice & 5 & 1.32 & 1.30 & 1.35 & 500 & 6.61 \\
\hline Roast pork with dumplings & 2 & 2.03 & 1.99 & 2.07 & 380 & 7.72 \\
\hline Minced meat with mashed potatoes & 2 & 1.43 & 1.36 & 1.50 & 330 & 4.72 \\
\hline Fillet of pork with rice & 2 & 1.51 & 1.35 & 1.67 & 350 & $5 \cdot 30$ \\
\hline Pork with cabbage and potatoes & 2 & 1.40 & 1.33 & 1.46 & 330 & 4.59 \\
\hline Kebab meat with rice and sauce & 5 & 1.35 & 1.21 & 1.46 & 400 & 5.40 \\
\hline Beef stroganoff with rice & 5 & 1.12 & 1.09 & 1.15 & 455 & $5 \cdot 10$ \\
\hline Beef goulash with spaetzle & 2 & 1.48 & 1.47 & 1.48 & 400 & 5.90 \\
\hline Pasta with sauce Bolognese & 2 & 1.07 & 0.99 & $1 \cdot 15$ & 350 & 3.74 \\
\hline Beef roulade with pasta & 2 & 1.53 & 1.52 & 1.54 & 375 & 5.75 \\
\hline Venison ragout with dumplings & 2 & 1.86 & 1.81 & 1.91 & 330 & $6 \cdot 13$ \\
\hline Aelpler Makkaronen & 5 & 1.40 & 1.38 & 1.43 & 350 & 4.90 \\
\hline Mashed potatoes, kale and sausage & 5 & 1.37 & 1.32 & 1.42 & 500 & $6 \cdot 84$ \\
\hline Lentil stew with dumplings & 2 & 1.57 & 1.55 & 1.59 & 350 & $5 \cdot 50$ \\
\hline Filled dumplings with sauerkraut & 2 & 1.53 & 1.52 & 1.54 & 350 & $5 \cdot 37$ \\
\hline Goulash with sausages and potatoes & 2 & 1.53 & 1.52 & 1.53 & 350 & $5 \cdot 34$ \\
\hline Salmon with potatoes and sauce & 5 & 0.85 & 0.83 & 0.88 & 490 & 4.18 \\
\hline Salmon with pasta and vegetables & 5 & 0.71 & 0.67 & 0.74 & 500 & 3.54 \\
\hline Salmon with pasta and spinach & 2 & 1.41 & $1 \cdot 18$ & 1.64 & 350 & 4.93 \\
\hline Catfish with ratatouille and rice & 2 & 1.20 & 1.17 & 1.22 & 350 & $4 \cdot 19$ \\
\hline Pollack with rice & 2 & 1.56 & 1.52 & 1.60 & 380 & 5.93 \\
\hline Pasta with spicy tomato sauce & 2 & 1.47 & 1.40 & 1.54 & 330 & 4.85 \\
\hline Pasta with tomato-mozzarella sauce & 2 & 1.46 & 1.45 & 1.46 & 400 & $5 \cdot 82$ \\
\hline \multicolumn{7}{|l|}{ Newly developed ready meals } \\
\hline Chicken with rice and vegetables & 5 & 0.78 & 0.74 & 0.81 & 470 & 3.65 \\
\hline Pork with mashed potatoes, carrots & 5 & 1.21 & $1 \cdot 15$ & 1.27 & 360 & 4.34 \\
\hline Pork with mashed potatoes, broccoli & 5 & 1.26 & 1.21 & 1.28 & 360 & 4.52 \\
\hline Lamb with sauce, rice and vegetables & 5 & 0.64 & 0.61 & 0.70 & 470 & 3.00 \\
\hline Salmon with pasta and cauliflower & 5 & 0.58 & 0.55 & 0.60 & 470 & 2.73 \\
\hline Salmon with potatoes and broccoli & 5 & 0.56 & 0.54 & 0.58 & 440 & 2.47 \\
\hline Pasta with spinach-ricotta filling & 5 & 1.27 & 1.24 & 1.32 & 380 & 4.83 \\
\hline
\end{tabular}

${ }^{*}$ One serving is equivalent to the package size.

†The package sizes of two meals were larger than one serving and therefore their portion sizes were estimated.

ready meals analysed were designed to replace one complete main course $(=30 \%$ of the RDA), their nutritional values were assessed by comparing the salt concentrations with both $30 \%$ and $100 \%$ of the targeted average daily salt intake for adults.

As shown in Table 3, all ready meals analysed exceeded $30 \%$ of the targeted average daily salt intake, which depending on the reference is either $1.8 \mathrm{~g}^{(4-8)}$ or $1.5 \mathrm{~g}^{(3)}$. More than $50 \%$ of the meals exceeded the more restrictive targeted daily intake level of $5 \mathrm{~g}^{(3)}$ and almost $20 \%$ were above the more liberally set $6 g^{(4-8)}$.

Comparison of our data with studies from the UK and Australia

As reported, high salt levels in all analysed continental European ready meals were found. In comparison with a survey of 265 Australian ready meals that showed a mean salt content of $0.70 \mathrm{~g} / 100 \mathrm{~g}$ and a maximum value of $1.98 \mathrm{~g} / 100 \mathrm{~g}^{(32)}$, the average salt content analysed in the present study was higher, but the maximum levels were in the same range.

Back in 2003 ready meals with nearly $6 \mathrm{~g}$ salt per serving were also available on the British market ${ }^{(39)}$. However, four years later, after having implemented a national-wide governmentally led salt reduction campaign that combined consumer education, front-of-pack labelling and a voluntary food reformulation process ${ }^{(36)}$, the average salt content of ready meals was successfully reduced to $0.49 \mathrm{~g} / 100 \mathrm{~g}$, with no meal containing more than $1 \mathrm{~g} / 100 \mathrm{~g}$. Regarding the portion size only $7 \%$ of the meals exceeded $3 \mathrm{~g}$ salt/serving, which is half of an adult's maximum daily recommended intake ${ }^{(33)}$. 
Thus, for ready meals in the UK combined governmental and food industrial efforts achieved a significant reduction of the meals' average salt contents from 2003 to $2007^{(33)}$. In contrast, average salt reduction in Australian ready meals failed ${ }^{(32)}$. The authors of the study identified as a major reason for the failure the lack of any coordinated salt reduction strategies from industry as a consequence of the missing governmental leadership. Until now there are still no salt reduction targets for ready meals set in Australia. Additionally, the programme is voluntary and there is no systemic and objective monitoring ${ }^{(32)}$.

The results of our study indicate that the salt contents of all analysed continental European ready meals are too high. Therefore, the next step within the project was to develop new salt-reduced ready meals in cooperation with food-producing companies. The results of this food reformulation process are presented in the following section.

\section{Nutrient composition of newly developed ready meals (n 7)}

Establishing basic nutritional guidelines for the meal reformulation process

Easily understandable recommendations for the food producers to develop healthier meals with lower salt contents were established and together with other guidelines for improving the nutritional quality of ready meals, were published in various continental European trade journals, either in print or on the journals' web sites ${ }^{(40)}$ to reach as many companies and retailers as possible. Regarding the salt content, the overall message was to use salt only in a limited amount and to improve taste with alternatives such as spices and herbs. We also emphasized the importance of a low amount of salt for the development of child-specific ready meals to avoid that children's taste adapts on salty.

\section{Salt contents in g/100g and in g/portion}

The mean salt content of the newly developed meals was $0.90 \mathrm{~g} / 100 \mathrm{~g}$, ranging from 0.56 to $1.27 \mathrm{~g} / 100 \mathrm{~g}$. In comparison to the previously available ready meals that had been analysed, their salt levels were significantly lower (0.9 g/100 g v. $1.38 \mathrm{~g} / 100 \mathrm{~g} ; P=0.001)$, which refers to an effective implementation of meal reformulation guidelines.

Taking the portion size into account, the salt content varied from 2.47 to $4.83 \mathrm{~g} /$ serving, with a mean of $3.65 \mathrm{~g} /$ serving. There were no meals exceeding previously mentioned targeted daily intake levels ${ }^{(3-8)}$. However, all newly developed ready meals yet exceeded the $30 \%$ threshold of the recommendations for one main meal (Table 3).

Furthermore, the sensory attributes of two newly developed ready meals were tested in a consumer panel with 112 Norwegian adults (46\% males and $54 \%$ females; $38 \% 24-39$ years of age, $42 \% 40-55$ years of age and $20 \%$ 56-72 years of age). Despite their lower salt concentration 
Table 3 Proportion of analysed ready meals exceeding $30 \%$ and $100 \%$ of targeted average salt intake per day

\begin{tabular}{|c|c|c|c|c|}
\hline & \multicolumn{2}{|c|}{ Currently available ready meals } & \multicolumn{2}{|c|}{ Newly developed ready meals } \\
\hline & No. of meals & $\%$ of meals & No. of meals & $\%$ of meals \\
\hline \multicolumn{5}{|c|}{ Meals exceeding $30 \%$ of recommendations } \\
\hline Most expert committees* ${ }^{*}$ & 32 & 100 & 7 & 100 \\
\hline WHO† & 32 & 100 & 7 & 100 \\
\hline \multicolumn{5}{|c|}{ Meals exceeding $100 \%$ of recommendations } \\
\hline Most expert committees* & 6 & 19 & 0 & 0 \\
\hline WHOt & 17 & 53 & 0 & 0 \\
\hline
\end{tabular}

*Sources: Scientific Advisory Committee on Nutrition (2003); Deutsche Gesellschaft für Ernährung et al. (2000); Eurodiet (2000); Health Council of the Netherlands (2006); Nordic Council of Ministers $(2004)^{(4-8)}$.

†Source: WHO (2012) ${ }^{(3)}$.

overall consumer acceptance including the flavour of both meals was rated very high $(5.0$ and 5.7 , respectively, on a scale $1=$ very dissatisfied and $7=$ very satisfied $)^{(41)}$.

In summary, our results show that a stepwise salt reduction through the process of meal reformulation is necessary and achievable. Additionally, the data of the two sensory tested ready meals (chicken with rice and vegetables; salmon with pasta and cauliflower) suggest the possibility of salt reduction without compromising the sensory quality and shelf life of the products.

\section{Comprebensive survey of Austrian convenience foods (n 572)}

Nutrient declaration labels on 572 convenience foods from the Austrian market were collected. Sodium or salt contents were available for only 233 products ( $41 \%$ of all). The overall average level of all convenience foods was $1.07 \mathrm{~g}$ salt/100 g or 3.18 g salt/portion (Table 2).

Differences in salt content by meal type category and meal-producing company

As is shown in Table 2 pizzas had the highest salt content, followed by pasta dishes and savoury dumplings. Pizzas and pasta dishes contained significantly more salt per serving than soups $(P<0 \cdot 001)$ and sweet meals $(P<0 \cdot 001)$. Furthermore the pizzas' salt contents were higher than those of meat meals $(P<0.001)$, fish meals $(P<0.001)$ and cold meals $(P<0.001)$. Data from Australia and the UK collected from 2007 to 2009 report similar salt levels for pizzas ${ }^{(21,29,31)}$ as were found within the present study. The lowest median salt content was found in sweet meals, followed by soups, 'other meals' and fish meals.

Variations of salt in apparently similar convenience meals Interestingly, large variations were found not only between the different meal type categories, but also within meal groups (Table 2). Additionally, the salt contents of apparently similar ready meals produced by different companies were found to vary explicitly. For instance, a chilled pasta Bolognese showed a much lower salt content of $0.51 \mathrm{~g} / 100 \mathrm{~g}$ as compared with another company's analogous meal having $1.27 \mathrm{~g} \mathrm{salt} / 100 \mathrm{~g}$. This variation was also mirrored in other meal type categories. In the soups category, for instance, two competitive alphabet soups containing 1.02 and $1.53 \mathrm{~g}$ salt/100 g were found.

For pizzas some products that were advertised as fat reduced and supposedly healthier were found to be higher in salt $(1.73 \mathrm{~g} / 100 \mathrm{~g})$ than the standard versions ( $1.53 \mathrm{~g} / 100 \mathrm{~g} ; 12 \%$ less salt).

Although sweet meals on average had the lowest salt levels, a typical Austrian dish called Mohnnudeln (potato noodles with melted butter and poppy seeds) was one of the meals with the highest salt content of all $(6 \cdot 36 \mathrm{~g} / 100 \mathrm{~g})$. However, similar meals of competing companies showed a considerably lower salt content of $0.25 \mathrm{~g} / 100 \mathrm{~g}$ (Mohnnudeln with apple sauce).

The discussed variations found in the present study were also observed in other studies from the UK and Australia ${ }^{(32,33)}$.

Comparison of the salt contents in g/portion with the targeted daily salt intake levels

Our results show that the salt contents of approximately $90 \%$ of all investigated Austrian convenience products exceeded $30 \%$ of the recommended targeted daily salt intake levels ${ }^{(3-8)}$ (Table 2). In seven out of eleven meal type categories (e.g. pizzas, pasta dishes or soups) all sampled meals contained more salt per portion relative to the targeted intake level of $1.5 \mathrm{~g}$.

Twenty-one per cent of all meals, $52 \%$ of pizzas, $33 \%$ of pasta dishes and $14 \%$ of meat meals had even higher salt concentrations than what is targeted by the WHO $(5 \mathrm{~g} / \mathrm{d})$.

In summary, our results demonstrate that despite the above discussed large variations nearly all convenience products from the Austrian market are too high in salt.

\section{Public bealth aspect}

Our study proves that the salt contents of continental European ready meals and in particular those of Austrian convenience foods mostly exceed the targeted intake levels defined for one main meal (30\%) and some even the daily recommended dose (100\%). As the negative health effects of a high salt intake are well known and convenience foods play an important role in the daily diet, a salt reduction is crucial.

Most salt was found in pizzas and pasta dishes, the lowest concentrations in sweet meals. Large variations of the salt 
levels (in total from $0 \cdot 23$ to $7 \cdot 37 \mathrm{~g} / 100 \mathrm{~g}$ ) were found not only between and within the different meal type categories, but also between similar meals from different companies. In one case, for instance, a pasta dish contains $149 \%$ more salt than the same meal from a competitive producer.

Furthermore, our data suggest that a stepwise reduction of the ready meals' salt content by meal reformulation is feasible without compromising the sensory quality. This is supported by successful salt reduction programmes implemented in the UK and Finland ${ }^{(33,35,36)}$ and confirmed by a study on fast food ${ }^{(25)}$. That study's authors concluded that in the right regulatory context fast-food producers are probably able to reduce their products' salt contents considerably.

In Austria, however, there is no regulatory approach for reducing the salt content of convenience products in place. Moreover, a media campaign to raise consumer awareness regarding the negative impact of a high-salt diet on human health is missing and in $40 \%$ of the meals declaration of the sodium and/or salt content is unavailable. This makes it difficult for consumers to choose between low- and high-salt options.

The current issue of high salt contents is comparable to the high levels of trans-fatty acids in convenience products and fast foods some years ago. Comprehensive investigations on the trans-fatty acid contents of various Austrian products confirmed that a harmful intake of trans-fatty acids was possible ${ }^{(42)}$. From there on, the government regulated the allowed amount of trans-fatty acids in foods by law ${ }^{(43)}$. This led to national-wide food reformulations by the food industry with the consequence that there are hardly any products with high trans-fatty acid levels on the market any longer.

Food reformulation is a 'key option to achieve population nutrition goals, ${ }^{(44)}$ and so far some examples such as the Finnish salt reduction initiative have shown positive effects on human health. A key part of this initiative is the mandatory salt labelling which led to the disappearance of many highly salted foods from the market and a greater variety of salt-reduced products ${ }^{(45)}$. Thereby, the public health initiatives in Finland led to a significantly lower salt intake that is reflected by a decrease in the $24 \mathrm{~h}$ urinary sodium excretion during the last 20 years $^{(46)}$. Besides, a reduction in the average blood pressure by more than $10 \mathrm{mmHg}$ and a $75 \%$ to $80 \%$ decrease in mortality from both stroke and CHD could be observed ${ }^{(47)}$. These results are specifically important with regard to a different Finnish cohort study, which showed that a $100 \mathrm{mmol}$ higher $24 \mathrm{~h}$ urinary sodium excretion led to a $51 \%$ increased risk for CHD, a $45 \%$ increased risk for CVD and a $26 \%$ increased risk for all-cause mortality ${ }^{(48)}$.

Asaria et $a l .{ }^{(9)}$ demonstrated that 8.5 million cardiovascular deaths in twenty-three countries could be averted by a $15 \%$ mean population salt intake reduction over a period of 10 years. The costs for implementing an adequate salt reduction programme were estimated to be \$US 0.09 per person per year.

\section{Conclusion}

A governmental-led strategy as is successfully established in the UK or Finland would be a good option to lower the salt content of Austrian and Central European convenience products including ready meals. Based on studies from the UK, Finland and Australia, it seems that legislation with either governmentally set salt reduction targets for various food groups or with mandatory labelling of the salt contents would be a more efficient way to successfully reduce the salt concentrations of foods than a voluntary-based programme without any monitoring.

Either way, an effective governmental-led salt reduction programme would result in a population-wide lower salt intake with a beneficial impact on blood pressure. Thus medical care costs and lives could be saved through the prevention of CVD.

\section{Acknowledgements}

Financial support: This work was supported by the European Commission within the 6th Framework Programme, under the Priority 5 'Food quality and safety' (grant number FOOD-CT-2006-23182); and the Austrian Chamber of Labour. The European Commission and the Austrian Chamber of Labour had no role in study design, analysis or writing of this article. Conflict of interest: None. Authorship: S.K. and K.-H.W. designed the study; S.K., A.G. and G.L. did the laboratory analyses; C.H. collected the package information of the Austrian convenience meals; S.K. conducted data interpretation and wrote the article; K.H.-W. made critical comments on the drafts and received the grants.

\section{Supplementary material}

To view supplementary material for this article, please visit http://dx.doi.org/10.1017/S1368980014000731

\section{References}

1. World Health Organization (2011) Global Status Report on Non-Communicable Diseases 2010. Geneva: WHO.

2. He FJ \& MacGregor GA (2010) Reducing population salt intake worldwide: from evidence to implementation. Prog Cardiovasc Dis 52, 363-382.

3. World Health Organization (2012) Guideline: Sodium Intake for Adults and Children. Geneva: WHO.

4. Scientific Advisory Committee on Nutrition (2003) Salt and Health. London: The Stationery Office.

5. Deutsche Gesellschaft für Ernährung, Österreichische Gesellschaft für Ernährung, Schweizerische Gesellschaft für Ernährungsforschung et al. (2013) D-A-CH Referenzwerte für die Nährstoffzufubr. Frankfurt am Main: Umschau Braus Verlag.

6. Eurodiet (2000) Nutrition \& Diet for Healthy Lifestyles in Europe: Science \& Policy Implications. Eurodiet Core Report. Crete: Eurodiet.

7. Health Council of the Netherlands (2006) Guidelines for a Healthy Diet 2006. The Hague: Health Council of the Netherlands. 
8. Nordic Council of Ministers (2004) Nordic Nutrition Recommendations (NNR) 2004. Integrating Nutrition and Physical Activity. Copenhagen: Nord.

9. Asaria P, Chisholm D, Mathers C et al. (2007) Chronic disease prevention: health effects and financial costs of strategies to reduce salt intake and control tobacco use. Lancet 370, 2044-2053.

10. Bibbins-Domingo K, Chertow GM, Coxson PG et al. (2010) Projected effect of dietary salt reductions on future cardiovascular disease. $N$ Engl J Med 362, 590-599.

11. Joffres MR, Campbell NRC, Manns B et al. (2007) Estimate of the benefits of a population-based reduction in dietary sodium additives on hypertension and its related health care costs in Canada. Can J Cardiol 23, 437-443.

12. Murray CJL, Lauer JA, Hutubessy RCW et al. (2003) Effectiveness and costs of interventions to lower systolic blood pressure and cholesterol: a global and regional analysis on reduction of cardiovascular-disease risk. Lancet $\mathbf{3 6 1}$, $717-725$.

13. Selmer RM, Kristiansen IS, Haglerod A et al. (2000) Cost and health consequences of reducing the population intake of salt. J Epidemiol Community Health 54, 697-702.

14. Brown IJ, Tzoulaki I, Candeias V et al. (2009) Salt intakes around the world: implications for public health. Int $J$ Epidemiol 38, 791-813.

15. Elmadfa I, Hasenegger V, Wagner K et al. (2012) Österreichischer Ernährungsbericht 2012. Vienna: Federal Ministry of Health.

16. James WP, Ralph A \& Sanchez-Castillo C (1987) The dominance of salt in manufactured food in the sodium intake of affluent societies. Lancet 1, 426-429.

17. Mattes RD \& Donnelly D (1991) Relative contributions of dietary sodium sources. J Am Coll Nutr 10, 383-393.

18. Anderson CAM, Appel LJ, Okuda N et al. (2010) Dietary sources of sodium in China, Japan, the United Kingdom, and the United States, women and men aged 40 to 59 years: the INTERMAP study. $J$ Am Diet Assoc 110, 736-745.

19. DeSimone JA, Beauchamp GK, Drewnowski A et al. (2013) Sodium in the food supply: challenges and opportunities. Nutr Rev 71, 52-59.

20. Food Standards Agency \& Department of Health (2011) National Diet and Nutrition Survey. Headline Results from Years 1 and 2 (combined) of the Rolling Programme (2008/ 2009-2009/2010) [B Bates, A Lennox, C Bates et al., editors]. London: NatCen, UCL and MRC Human Nutrition Research; available at https://www.gov.uk/government/ uploads/system/uploads/attachment_data/file/216484/dh_ 128550.pdf

21. Ni Mhurchu C, Capelin C, Dunford EK et al. (2011) Sodium content of processed foods in the United Kingdom: analysis of 44,000 foods purchased by 21,000 households. Am J Clin Nutr 93, 594-600.

22. Costa AIdA, Schoolmeester D, Dekker M et al. (2007) To cook or not to cook: a means-end study of motives for choice of meal solutions. Food Qual Prefer 18, 77-88.

23. Jabs J \& Devine CM (2006) Time scarcity and food choices: an overview. Appetite 47, 196-204.

24. Wagner KH \& Brath H (2012) A global view on the development of non communicable diseases. Prev Med 54, Suppl., S38-S41.

25. Dunford E, Webster J, Woodward M et al. (2012) The variability of reported salt levels in fast foods across six countries: opportunities for salt reduction. CMAJ 184, 1023-1028.

26. Jaworowska A, Blackham T, Stevenson L et al. (2012) Determination of salt content in hot takeaway meals in the United Kingdom. Appetite 59, 517-522.

27. Scourboutakos MJ \& L'Abbé MR (2013) Sodium levels in Canadian fast-food and sit-down restaurants. Can J Public Health 104, e2-e8.
28. Wellard L, Glasson C \& Chapman K (2012) Fries or a fruit bag? Investigating the nutritional composition of fast food children's meals. Appetite 58, 105-110.

29. Grimes CA, Nowson CA \& Lawrence M (2008) An evaluation of the reported sodium content of Australian food products. Int J Food Sci Technol 43, 2219-2229.

30. Tanase CM, Griffin P, Koski KG et al. (2011) Sodium and potassium in composite food samples from the Canadian Total Diet Study. J Food Compost Anal 24, 237-243.

31. Webster JL, Dunford EK \& Neal BC (2010) A systematic survey of the sodium contents of processed foods. Am J Clin Nutr 91, 413-420.

32. Christoforou AK, Dunford EK \& Neal BC (2013) Changes in the sodium content of Australian ready meals between 2008 and 2011. Asia Pac J Clin Nutr 22, 138-143.

33. Consensus Action on Salt and Health (2007) Salt in UK ready meals $45 \%$ lower than four years ago. http://www.action onsalt.org.uk/news/surveys/2007/ready/index.html (accessed June 2013).

34. He FJ \& MacGregor GA (2009) A comprehensive review on salt and health and current experience of worldwide salt reduction programmes. J Hum Hypertens 23, 363-384.

35. Mohan S, Campbell NRC \& Willis K (2009) Effective population-wide public health interventions to promote sodium reduction. CMAJ 181, 605-609.

36. Webster JL, Dunford EK, Hawkes C et al. (2011) Salt reduction initiatives around the world. J Hypertens 29, 1043-1050.

37. Costa AIA, Dekker M, Beumer RR et al. (2001) A consumeroriented classification system for home meal replacements. Food Qual Prefer 12, 229-242.

38. Matissek R \& Steiner G (2006) Lebensmittelanalytik Grundzüge, Methoden, Anwendungen. Berlin/Heidelberg/ New York: Springer Verlag.

39. Food Standards Agency (2003) High salt levels found in ready meals. http://webarchive.nationalarchives.gov.uk/ 20101224202640/http://food.gov.uk/news/newsarchive/2003/ jun/saltinreadymeals (accessed June 2013).

40. Kanzler S \& Wagner KH (2009) Guidelines for the improvement of the nutritional quality of ready meals in Europe. Die Ernäbrung 33, 13-15.

41. Olsen NV, Menichelli E, Sørheim O et al. (2012) Likelihood of buying healthy convenience food: an at-home testing procedure for ready-to-heat meals. Food Qual Prefer 24, 171-178.

42. Wagner KH, Plasser E, Proell C et al. (2008) Comprehensive studies on the trans fatty acid content of Austrian foods: convenience products, fast food and fats. Food Chem 108, 1054-1060.

43. Bundeskanzleramt Rechtsinformationssystem (2009) Verordnung des Bundesministers für Gesundheit über den Gehalt an trans-Fettsäuren in Lebensmitteln (Trans-FettsäurenVerordnung). BGBl. II Nr. 267/2009. http://www.ris.bka.gv.at/ GeltendeFassung.wxe?Abfrage $=$ Bundesnormen $\&$ Gesetze snummer $=20006420 \&$ ShowPrintPreview $=$ True (accessed July 2013).

44. Van Raaij J, Hendriksen M \& Verhagen H (2009) Potential for improvement of population diet through reformulation of commonly eaten foods. Public Health Nutr 12, 325-330.

45. Pietinen P, Valsta LM, Hirvonen T et al. (2008) Labelling the salt content in foods: a useful tool in reducing sodium intake in Finland. Public Health Nutr 11, 335-340.

46. Laatikainen T, Pietinen P, Valsta L et al. (2006) Sodium in the Finnish diet: 20-year trends in urinary sodium excretion among the adult population. Eur J Clin Nutr 60, 965-970.

47. Karppanen H \& Mervaala E (2006) Sodium intake and hypertension. Prog Cardiovasc Dis 49, 59-75.

48. Tuomilehto J, Jousilahti P, Rastenyte D et al. (2001) Urinary sodium excretion and cardiovascular mortality in Finland: a prospective study. Lancet 357, 848-851. 